\title{
The Extent of Participation in Urban Agriculture and Its Effect on Food Security in Africa and Asia: Evidence from Ghana and India
}

Richard Kwasi Bannor ( $\nabla$ richard.bannor@uenr.edu.gh )

University of Energy and Natural Resources https://orcid.org/0000-0003-4651-6064

Mohit Sharma

Dr Rajendra Prasad Central Agricultural University

Helena Oppong-Kyeremeh

University of Energy and Natural Resources

\section{Research}

Keywords: urban agriculture, food security, Seemingly Unrelated Regression, HFIAS, per capita food expenditure

Posted Date: August 10th, 2020

DOl: https://doi.org/10.21203/rs.3.rs-52761/v2

License: (c) (i) This work is licensed under a Creative Commons Attribution 4.0 International License. Read Full License 
The authors have withdrawn this preprint from Research Square 